\title{
A Survey on the Engineering Interdisciplinary Postgraduate Education Based on Engineering with a Big E
}

\author{
Zhuoping $\mathrm{Wu}$ \\ Faculty of Humanities and Social Sciences \\ Dalian University of Technology \\ Dalian, P.R. China \\ e-mail: wuzhuoping1987@126.com
}

\author{
Songchan Wang \\ Faculty of Humanities and Social Sciences \\ Dalian University of Technology \\ Dalian, P.R. China \\ e-mail: wangsongchan@163.com
}

\author{
Liansheng Yang \\ Faculty of Humanities and Social Sciences \\ Dalian University of Technology \\ Dalian, P.R. China \\ e-mail: 84707554@163.com
}

\begin{abstract}
Some questions exist in the development of Chinese engineering interdisciplinary postgraduate education, such as little attention to the guidelines on engineering education, lack of practice-oriented engineering training, loose cooperation between school and enterprise, little attention to the cultivation of students' innovation ability. Engineering with a Big $\mathbf{E}$ emphasizes integration of knowledge and practice, creativeness and system on engineering, which provides an important basis for exploring engineering interdisciplinary graduate education in our country. The discussion on engineering interdisciplinary graduate education is based on the idea of Engineering with a Big $\mathbf{E}$, which is aimed at making engineering interdisciplinary postgraduate students face complex engineering environment based on the theoretical study and become a creative person in the work of engineering practice with high ability and quality. As a high-level engineering and technological person, the engineering interdisciplinary postgraduate students are required to play a greater role in the progress of society.
\end{abstract}

Keywords-Higher engineering education; Engineering; Postgraduate; Engineering interdisciplinary postgraduate; Postgraduate education; Engineering with a Big E

\section{INTRODUCTION}

The focus of competition in the field of engineering lies in the engineering talents competition throughout all countries and regions. The size, quality and structure of the engineering and technological personnel determine the engineering technology development of a country or a region. With the development of new interdisciplinary groups, the synthetic efforts composed by many disciplines promote the continuous development of engineering practice, which will make the engineering practice in the future involve more complicated multi-discipline backgrounds and diversified forms. It is required in higher engineering education to pay attention to the frontier, times and innovation, to overcome barriers, to strengthen interdisciplinary research, to adjust the training system according to the changes in reality, and to focus on sustainable development of training talents. As an important part of higher engineering education, engineering interdisciplinary graduate education should adapt training mechanism to the contemporary development so as to meet the demands of engineering practice. The discussion on engineering interdisciplinary graduate education is based on the idea of Engineering with a Big E, which is aimed at making engineering interdisciplinary postgraduate students face complex engineering environment based on the theoretical study and become a creative person in the work of engineering practice with high ability and quality ${ }^{[1]}$. As the important group in the engineering postgraduate students, engineering interdisciplinary ones have a lot of their own characteristics. It is a valuable question to discuss how to guide the engineering interdisciplinary postgraduate students, as the high-level engineering and technological person, to make greater contribution to the progress of society with the idea of Engineering with a Big E. 


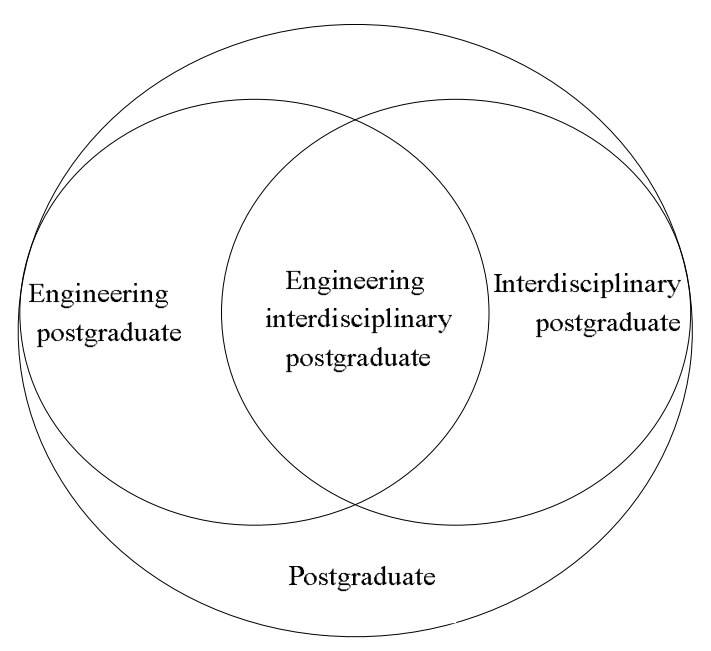

Fig.1 The discipline position of Engineering interdisciplinary postgraduate

\section{THE INSPIRATION OF ENGINEERING WITH A BIG E ON} ENGINEERING INTERDISCIPLINARY POSTGRADUATE EDUCATION

\section{A. Engineering with a Big $E$}

Since 1990, the movement of "back to engineering" in the USA has set off a new wave of higher engineering education reform. In 1993, Moore, the president of Massachusetts Institute of Technology, proposed the idea of Engineering with a Big E. In 1994, Dean Joel Moses, the leader of the School of Engineering in Massachusetts Institute of Technology, made a long range plan for the School of Engineering called Engineering with a Big $\mathrm{E}$ and Integrative Education in Engineering. He believes that the idea of Engineering with a $\mathrm{Big} \mathrm{E}$ is a return of engineering education for real engineering service, and is opposite to research-oriented engineering science [2]. In 1995, in the report called Reconstruction of Engineering Education: Focus on Reform -- Special NSF Engineering Education Seminar report, which is published on American National Science Foundation, Engineering with a Big E has been fully embodied, emphasizing the complete and systematic knowledge. The idea of Engineering with a Big E claims that since the modern project is a complicated system, in order to solve the problem of modern engineering, engineering talents should break the discipline barriers and revert what has been separated to a whole project. The higher engineering education should not only make students study engineering knowledge and theories, but also make them contact with complex system analysis and management in large scale. By this way can they not only integrate knowledge, but also enhance understanding on the economics, society, politics and technical system.

The idea of Engineering with a Big E, being taken as the result of the movement of "back to engineering", leads a new direction for the future development of engineering education, gains widespread support of society, develops gradually and becomes the guidance of higher engineering education.

\section{B. Engineering Interdisciplinary Postgraduate Education}

Engineering interdisciplinary postgraduate education is aimed at improving the practical ability of students. During course of postgraduate training, two or more than two disciplines' knowledge is integrated and complementary effect is made, by joint planning among disciplines and setting training target, which is based on a common understanding of the actual and potential value of a certain subject and mutual respect. Engineering interdisciplinary postgraduate students are made up of master and doctor of engineering on professional degree and master and doctor of engineering on academic degree, who take interdisciplinary as the training platform. As the cognition of engineering education improves in China, the engineering postgraduate education has been gradually moving towards the right track. It has become an important part of postgraduate education system to cultivate high-level specialized talents. Engineering interdisciplinary postgraduate students, as the persons in engineering practice, their education is not only related to the comprehensive development of themselves, but also important factor restricting the level of engineering practice, which determines the development of national engineering technology and its sustainable development.

\section{Inspiration of Engineering with a Big E on engineering interdisciplinary postgraduate education}

According to the related research at home and abroad, the temporary research on interdisciplinary graduate education mainly is focused on interdisciplinary training model, training mechanism, illustrating the merits and demerits of interdisciplinary training research at home and abroad. The discussion of training engineering interdisciplinary students sporadically appears in those articles, and the systematic research on the engineering interdisciplinary postgraduates is rare. It has just started in our country as to how to overcome the discipline barriers and form the efficient engineering interdisciplinary postgraduate training mechanism. In 1996, China National Engineering Education delegation to America published two articles: Return to engineering • Diversification • Macro management -- United States Investigation Report to America and Returning Project and American Reform of Higher Engineering Education, which firstly proposed the idea of Engineering with a Big E in China. Subsequently, the domestic academic circles extend the idea of Engineering with a Big E. On the basis of those studies, this paper argues that the idea of Engineering with a Big E, which highlights integrity and system, provides an important basis for engineering interdisciplinary postgraduate education. Based on the idea and practical requirement of the engineering practice, this paper with clear clarification of the related concepts tries to analyze present situation of engineering interdisciplinary graduate education in China, the problems and deficiencies, in order to provide new ideas and basis for engineering interdisciplinary postgraduate education and reference suggestions for increasing engineering interdisciplinary training quality. What is more, it is also argued to promote relevant departments to increase attention to engineering interdisciplinary postgraduate education, to increase the human and material resources, to improve the comprehensive ability 
of engineering interdisciplinary postgraduate students and to provide intellectual support for social development.

\section{PRESENT SITUATION OF ENGINEERING}

\section{INTERDISCIPLINARY POSTGRADUATE EDUCATION}

\section{A. Little attention to the guidelines on engineering education}

Theory is the guide to practice, and thought is the guide to action. Since the higher engineering education in developed countries entered a mature stage, in terms of the relation of technology, engineering and science it is believed that engineering is not simply technology, nor the appendage to science [3]. In recent years, although engineering education in our country has made some achievement, still scholars have pointed out: "The engineering education in China is far from being a conscientious subject consciousness, which is still in the stage of America fifty or sixty's[4]." In China, it still exists that focusing on science while disregarding technology and scientists are great while the engineers are at the lower level. With the serious situation of academism and overscientification in higher engineering education of our country, the engineering technological person cultivated by the higher engineering education a certain degree cannot meet the real needs of the country, which is closely related to the formation of the system of engineering education guiding ideology. Lacking guidance of complete engineering education, engineering interdisciplinary postgraduate education has been fumbling for growth, without the idea of "Where are now, and where to go".

\section{B. Lack of practice-oriented engineering training and loose cooperation between school and enterprise}

The cultivation of engineering interdisciplinary postgraduate students should be oriented to engineering practice. However, in the engineering interdisciplinary postgraduate education there exists many problems, such as valuing science and disregarding engineering, valuing theories and disregarding practice, valuing the training in logical thinking and disregarding the cultivation of practical ability [5]. According to the reference news report, it is said that among 1.6 million young engineers in China, only $10 \%$ of them have practical abilities satisfying the work in Multi-National Corporation while $25 \%$ of graduates in India have received training and reached the international standard. The universities offer engineering technological persons for enterprises, and enterprises need them to develop the productive force. But the engineering education in China has been facing the problem of insufficient practice: in the professional training program practice teaching is still attached to the theory teaching, without a set of effective engineering practice teaching system. Because of various reasons, enterprises are rarely involved in engineering education in the universities. Effective cooperation does not exist between universities and enterprises in the cultivation of students.

\section{Little attention to the cultivation of students' innovation ability}

In June 5th, 2006, President Hu Jintao made speeches respectively in the thirteenth academician assembly of China academy of science and the eighth academician assembly of China Academy of Engineering. He said, "For cultivating students' innovative spirit and practical ability, the set of higher school curriculum should be reformed, teaching content renewed and the integration of theory and practice focused. We should attach great importance to technological science development and engineering practice ability, and improve the ability of convert the scientific and technological achievements into engineering application." According to the idea of Engineering with a Big E, innovation of interdisciplinary postgraduate students is the key to engineering education. Professor Von Carmen in California Institute of Technology of America said: "Scientists study the existing world, and engineers create the world in the future." Innovation is the eternal pursuit of the goal of engineering education, but the contemporary engineering interdisciplinary postgraduate education emphasizes too much on professional knowledge, without enhancing the innovative ability of students throughout the cultivation. At the same time, textbooks of professional courses in some universities are obsolete and cannot reflect the frontier in the field of engineering technology, let alone the coherence and system of teaching, all of which affect the cultivation of students' innovative ability ${ }^{[6]}$.

\section{THE DEVELOPMENT PATH OF ENGINEERING}

INTERDISCIPLINARY POSTGRADUATE EDUCATION BASED ON THE IDEA OF ENGINEERING WITH A BIG E

With the expansion of education, engineering interdisciplinary postgraduate students increase in a large scale. Therefore, the cultivation of them deserves much attention, as starting point and main part of temporary engineering education. Engineering with a Big E emphasizes integration of knowledge and practice, creativeness and system on engineering. According to the idea of Engineering with a Big E, the cultivation of engineering interdisciplinary postgraduate students can proceed from the following aspects.

\section{A. "Stones from other hills may serve to polish the jade of this one": learning experience form the USA}

America, as the power of higher education, attaches great importance to higher engineering education in the economic development, and continuously explores the new methods of cultivating high-level engineering technological persons who meet the times requirement. American is the first county to propose the idea of Engineering with a Big E. As early as in the 1930s, American has discussed the interdisciplinary education in colleges, and believed that the interdisciplinary education is good to the development of interdisciplinary technology, and to cultivate modern talents' thinking ability, researching ability and communicating ability. Since the 1970s, Harvard University, Stanford University, Massachusetts Institute of Technology and other universities have established interdisciplinary researches and teaching institutions. Up to now, most colleges in the USA has built interdisciplinary research centers, which are engaged in the interdisciplinary research, the creation of a comprehensive curriculum of Arts and Sciences, and comprehensive attention to curriculum system and teaching content. According to the America news and World Report, which has the world's most authoritative 
school ranking, among the top 10 universities ranked on engineering education in the USA in 2012, there are various forms of engineering postgraduate interdisciplinary education projects, and they cultivate engineering technological persons who are adapt to the complicated and changeable social environment. Under the guidance of Engineering with a Big E, We can learn the engineering interdisciplinary postgraduate education projects from Massachusetts Institute of Technology, Georgia Institute of Technology, Carnegie Mellon University, Michigan State University, Cornell University and other universities, whose main mode, successful experience, and inspiration on the engineering postgraduate interdisciplinary education reform in our country should be carefully summarized.

\section{B. "Stand on solid ground, back to practice": practice is the soul of engineering education}

Marx thought that the social life is practical in nature, and practice is the activities by people to understand the world and transform objective world, which is characterized by objectivity and material. Engineering education comes from the practice and also returns to practice. Focusing on practice has become the consensus of contemporary engineering education around the world. Joel Moses, President in Massachusetts Institute of Technology has pointed out: "The idea of Engineering with a Big E is a regression of engineering education to engineering services, and opposite to researchoriented engineering, which emphasizes the integrated and systematic knowledge." The purpose of the idea of Engineering with a Big $\mathrm{E}$ is to stress that engineering education must return to engineering and practice. Engineering practice is the important way of converting engineering knowledge into engineering interdisciplinary postgraduate students' practical ability. To train engineering interdisciplinary postgraduate students' practical ability, the proportion of practice must be increased in the teaching plan, which makes the students learn by doing practice. To achieve this goal, in addition to the engineering, interdisciplinary graduate curriculum design, practice, graduation design, elective courses, and other scientific settings, it is necessary to considerate the construction and management of teaching practice base and solve the cooperation dilemma between universities and companies [7]. Based on the master of basic engineering theories and professional knowledge, engineering interdisciplinary postgraduate students should be involved in practical engineering environment as much as possible and special training to improve their practical ability.

\section{C. "With great ambition, dare to innovate": innovation is the future of the development of engineering education}

Massachusetts Institute of Technology made the definition of modern engineering as follows: engineering is a creative major to meet the needs of the society in economics, human labors, politics and cultures and about the development and application on science and technology. Sue Home Linsky, famous educator and educational theorist in the former Soviet Union, said: "There exists a desire in the mind of every student making them discover, research and explore." Engineering interdisciplinary postgraduate students are important participants in engineering practice. By the establishment of high level innovative practical base of combination of production and study, construction of a long-term production training platform for engineering between University and enterprise, engineering interdisciplinary postgraduate students' creativity can be stimulated and the innovative development can be realized. Because of the different academic backgrounds of engineering interdisciplinary postgraduate students, interdisciplinary is required in the cultivation on interdisciplinary postgraduate students, and teachers need to pay attention to interdisciplinary subject knowledge system and teaching process. In order to develop innovative teaching in interdisciplinary engineering, we should reform traditional engineering education mode and break the traditional disciplinary boundaries and barriers of the institutes ${ }^{[8]}$.

\section{CONCLUSION}

The idea of Engineering with a Big $\mathrm{E}$ argues that engineering is systematic, comprehensive and creative, and engineering technological leading talents cultivated by higher engineering education should have interdisciplinary knowledge background and strong ability of engineering practice and engineering innovation. With interdisciplinary background, the engineering technological persons have more extensive background knowledge, more reasonable structure, and stronger adaptability and therefore have more chance to achieve innovative results. Interdisciplinary engineering postgraduate education must carry on the reform because it lies in the top level of higher engineering education with the responsibility for cultivating high-quality engineering and technological persons and is the main method to cultivate highlevel engineering technological persons. The idea of Engineering with a Big E is of fundamental significance for us to analyze engineering interdisciplinary postgraduate education [9]. The idea of Engineering with a Big E can lead the study of engineering interdisciplinary postgraduate education and help to find the training mechanism satisfying the needs of contemporary development, by which can we not only adapt to the needs of engineering practice, but also enrich the cultivating theories in the field of engineering technology in our country.

\section{ACKNOWLEDGMENT}

The work was Supported by the project of "Humanities and Social Science Foundation of Ministry of Education of China" (13JDGC008) "Study on the Functional Position of Engineering Training Center in Universities and its Teaching Models".

\section{REFERENCES}

[1] Li Anping, Chen Ruoyu and Hu Xiuying, "Discussion on Postgraduate Education Based on the Educational Idea of Largescale Engineering," The Modern Education Journal, vol. 3, Dec 2011,pp. 38-41. (In Chinese)

[2] Joel Moses, Engineering with a Big E: Integrative Education in Engineering. Massachusetts:S chool of Engineering Massachusetts Institute of Technology Cambridge, 1994.

[3] NAE, The Engineer of 2020:Visions of Engineering in the New Century. Washington DC: the National Academies, 2004. 
[4] Zhao Tingting and Mai Nannan, "The characteristic analyses of curriculum setting in America higher engineering education based on the idea of large-scale engineering," Journal of Higher Education, vol. 6, Dec. 2004, pp.94-101.(In Chinese).

[5] Wang Xuefeng and Cao Rong, "Engineering with A Big E and the Higher Engineering Educational Reform," Research in Higher Education of Engineering, vol. 4, Dec. 2006,pp.19-23. (In Chinese).

[6] Liu Jianguo and Liu Zhixin, "Educational Innovation of 'PanEngineering' in Engineering University," Journal of JiangSu Polytechnic University, vol 7, Dec. 2006,pp. 35-38.(In Chinese).

[7] Xie Xiaozhen, "An Exploration of the Connotation and Essential Features of "Large-scale Engineering," Research in Higher Education of Engineering, vol. 3, Dec. 2008, pp. 3538. (In Chinese).

[8] Zeng Lijuan, Du Min and Ma Yunkuo, " Exploration of the reform of Higher Engineering Education Based on Engineering with a BIG E," Education Exploration, vol. 9, Dec. 2013,pp. 3536. (In Chinese).

[9] Li Peigen, "Engineering Education Needs the View of Engineering with A Big E," Research in Higher Education of Engineering, vol. 3,Dec. 2011,pp. 1-3,59. (In Chinese). 